\title{
Effect of surface finishing on friction and wear of Poly-Ether-Ether-Ketone (PEEK) under oil lubrication
}

\author{
Thiago Fontoura de Andrade ${ }^{1 *}$, Helio Wiebeck² and Amilton Sinatora ${ }^{3}$ \\ ${ }^{1}$ Centro de Excelência em Engenharia, Eaton Grupo Veículo, Valinhos, SP, Brazil \\ ${ }^{2}$ Departamento de Engenharia Metalurgica e de Materiais, Escola Politécnica, \\ Universidade de São Paulo - USP, São Paulo, SP, Brazil \\ ${ }^{3}$ Laboratório de Fenômenos de Superfície - LFS, Departamento de Engenharia Mecânica, \\ Escola Politécnica, Universidade de São Paulo - USP, São Paulo, SP, Brazil \\ *thiagofandrade@eaton.com
}

\begin{abstract}
The tribological properties of poly-ether-ether-ketone (PEEK) containing 30\% of carbon fiber were studied in an oil-lubricated environment and different surface finishing of the metallic counterbody. Four different finishing processes, commonly used in the automotive industry, were chosen for this study: turning, grinding, honing and polishing. The test system used was tri-pin on disc with pins made of PEEK and counterbody made of steel; they were fully immersed in ATF Dexron VI oil. Some test parameters were held constant, such as the apparent pressure of $2 \mathrm{MPa}$, linear velocity of $2 \mathrm{~m} / \mathrm{s}$, oil temperature at $85^{\circ} \mathrm{C}$, and the time - 120 minutes. The lubrication regime for the apparent pressure of $1 \mathrm{MPa}$ to $7 \mathrm{MPa}$ range was also studied at different sliding speeds. A direct correlation was found between the wear rate, friction coefficient and the lubrication regime, wherein wear under hydrodynamic lubrication was, on average, approximately 5 times lower, and the friction coefficient 3 times lower than under boundary lubrication.
\end{abstract}

Keywords: tribology, PEEK, roughness, wear, friction.

\section{Introduction}

A major challenge for the use of polymeric materials in the mobility industry is the replacement of metallic materials used in the power train, especially the engine and transmission ${ }^{[1-3]}$. The conditions of torque, temperature and friction in the components of those systems render impractical the use of most polymers, nonetheless, there are some alternatives that can be studied, among those which poly-ether-ether-ketone (PEEK).

The combination of mechanical and wear resistance is one of the characteristics of PEEK which may allow its application in mechanical components such as gears, bearings, thrust washers, bushings, seals, forks, coupling elements, among others ${ }^{[4-6]}$. In order to enhance such properties even further; it is common to add carbon fiber to this polymer ${ }^{[7]}$. Thus, it is important to understand the tribological behavior of this material when in contact with metal parts with different roughness and in lubrication environments.

Originally, it was thought that less roughness meant less wear, due to abrasion, in polymers ${ }^{[8]}$. However, recent research has shown that for certain polymers there is an optimal roughness, pointing to a complex effect of the roughness of the counterbody in polymer wear.

Experiments conducted in dry condition with ultra-high molecular weight polyethylene (UHMWPE) rubbing against metallic parts with extremely smooth surfaces, have shown wear rates comparable to wear rates of parts rubbing against relatively rough surfaces. It is believed that, due to the reduced number and height of the asperities of the smoother surface, a thin film irregularly transferred from the work piece is formed, which functions as debris and accelerates abrasive wear. However, at a certain level of roughness, detached polymeric debris adhere to the valleys of the roughness, thereby reducing wear rate ${ }^{[9]}$.

Friedrich et al. ${ }^{[10]}$ studied the influence of roughness direction and parameters on dry wear. The study found that, when surface roughness is perpendicular to slip, natural PEEK does not change its wear characteristics with the increase of roughness $\mathrm{Ra}$, whereas, when surface roughness is parallel, there is a notable increase in the wear rate of PEEK without additives. For versions combined with fibers, the effects of counterbody roughness and relative slip direction were found to be less significant than that of regular PEEK.

The effect of controlled surface topography of metallic counterbodies in non-lubricated transfer and wear of PEEK was also studied by Ramachandra and Ovaert ${ }^{[11]}$. For that investigation, specimens were manufactured with longitudinal, transverse, and angled grooves, but no correlation among the angle of the channel, wear and friction coefficient was observed.

A well accepted model for polymer wear against very rough surfaces is simple abrasion, in which the metallic roughness penetrates the polymer up to a certain depth. The wear rate is determined by the depth of roughness penetration, shear angle and sliding distance. However, the wear rate changes with time because the asperities are covered by frayed polymer ${ }^{[12]}$.

Although a large number of the sliding friction studies conducted with this material were done in non-lubricated environments; sliding friction studies in lubricated environments 
are necessary. The objective of the present work was to evaluate friction and wear behavior of PEEK combined with $30 \%$ carbon fiber, in a lubricated environment, and with different roughness of metallic parts.

\section{Materials and Methods}

The present study was conducted using Victrex 150CA30-type which is PEEK matrix combined with $30 \%$ carbon fiber ${ }^{[13]}$. The pins were injected with a diameter of $5 \mathrm{~mm}$, as per ASTM G99-04 ${ }^{[14]}$, and at a temperature of approximately $380{ }^{\circ} \mathrm{C}$. The friction surface was smoothly polished using a $0.5 \mu \mathrm{m}$ sandpaper for 3 minutes in order to reduce remnant rough edges from injection molding, and correct friction surface planeness. The counterbody was manufactured with SAE 8620 steel, submitted to carburizing, quenching and tempering to a hardness range of 58-63 HRC. After heat treatment, the counterbody surface finish was achieved from four different processes: turning, grinding, honing and polishing.

\subsection{Friction test}

Polymer friction and wear behavior were analyzed using a three-pin on metallic disc tribometer sliding unidirectionally. The three-point contact was used to give greater stability for the rotation speed and strength used in the test. Tribological results obtained on tri-pin on disk test machines are generally different from those obtained from single-pin test machines. Single-pin tests tend to display stick-slip and preferential wear of pin edges. Three-pin on disc systems are particularly more suitable for the study of roughness on wear as they maintain the contact surface fairly constant after the initial running-in ${ }^{[7]}$.

The test was conducted in a lubricated environment with all the pins completely immersed in ATF Dextron VI oil and at a temperature of $85 \pm 5^{\circ} \mathrm{C}$ inside the test chamber. For each test, three new pins were placed onto the cylindrical device. The pins were positioned $120^{\circ}$ apart from each other and moved on the same track. Normal force was applied via a piezo-actuator on a servo-controlled mechanism. Thus, the capacitive sensor enabled normal force to be continuously monitored and compared with the nominal force of approximately $118 \mathrm{~N}$ (equivalent to an apparent contact pressure of $2 \mathrm{MPa}$ ), so that any variation could be immediately corrected. Rotational speed was $125 \mathrm{rad} / \mathrm{s}$, which corresponds to a linear speed of $2 \mathrm{~m} / \mathrm{s}$, also kept constant throughout the test. Test duration was defined after evaluation of wear over different sliding periods, until wear rate remained constant; this resulted in the adoption of a 120-minute period.

It is known that result variability is inherent to pin-on-disc friction tests; therefore, each test was repeated at least three times.

In order to obtain the friction coefficient curves versus sliding speeds, the samples slid for 60 minutes at a speed of $2 \mathrm{~m} / \mathrm{s}$ and pressure of $2 \mathrm{MPa}$, and were then subjected to constant pressure of $1 \mathrm{MPa}$ and $7 \mathrm{MPa}$. For each pressure, the pins were subjected to 10 different speeds for 10 minutes each. Initial speed was set at $1.2 \mathrm{~m} / \mathrm{s}$, and augmented, in arithmetic progression, at the rate of $1.2 \mathrm{~m} / \mathrm{s}$, for each step, up to $12 \mathrm{~m} / \mathrm{s}$. Through this experiment it was possible to ascertain the friction coefficient for each of the lubricating regime.

\subsection{Assessment of wear}

Specific wear rate $\left(W_{S}\right)$ expressed by Equation 1, was calculated through material mass loss $(\Delta \mathrm{m})$ obtained from the difference in pin mass before and after the test, divided by the load $(F)$, sliding distance $(L)$ and material density $(\rho)$.

$$
W_{s}=\frac{\Delta m}{F L \rho}\left(\frac{\mathrm{mm}^{3}}{\mathrm{Nm}}\right)
$$

\subsection{Roughness measurements}

Roughness measurements were conducted through white-light interferometry (Zygo Nexview). Typical topography for each of the finishing studied is shown on Figure 1 and the average linear roughness parameters are shown on Table 1, these parameters were obtained perpendicular to the sliding direction. Four measurements were obtained for each sample, $90^{\circ}$ apart.

\subsection{Microscopic assessment}

The friction surfaces of the polymeric pins and metallic counterbodies were analyzed with a stereomicroscope in order to investigate the mechanisms responsible for wear in each test.

\section{Results and Discussion}

\subsection{Definition of test duration}

The first factor to be considered was the definition of the duration of the test, in order to grantee that the system was in permanent wear regime. The test showed that, after 60 minutes, the mass loss remained stable for the two samples, when load, speed, surface finishing, lubrication and temperature conditions were maintained, as shown in Figure 2. Moreover, the mean friction coefficient for $\mathrm{N}=1$ and $\mathrm{N}=2$ did not vary significantly during the test (Figure 3 ), thus characterizing the permanent wear regime.

\subsection{Definition of the lubrication regime}

Figure 4 shows friction coefficient variation as a function of the sliding speed, with honing finishing. In Figure 4 it can be observed that, when submitted to constant contact pressure, the friction coefficient decreases as sliding speed increases, for both higher and lower pressures, with a sharper decrease for the latter. Thus, the lubrication regimes were defined for pressures between $1 \mathrm{MPa}$ and $7 \mathrm{MPa}$. For $1 \mathrm{MPa}$ the mixed regime occurs in a range of $1.2 \mathrm{~m} / \mathrm{s}$ to approximately $5 \mathrm{~m} / \mathrm{s}$, whereas for $7 \mathrm{MPa}$, the mixed regime only changes into hydrodynamic at $9 \mathrm{~m} / \mathrm{s}$. This occurs because in the sliding hydrodynamic regime the minimum lubrication film thickness is very sensitive to load. Base on the Stribeck curve, the friction coefficient range was defined for each lubrication regime, as follows: boundary regime 0.09 to 0.13 , mixed regime 0.04 to 0.09 and hydrodynamic regime lower than $0.04^{[15]}$. 

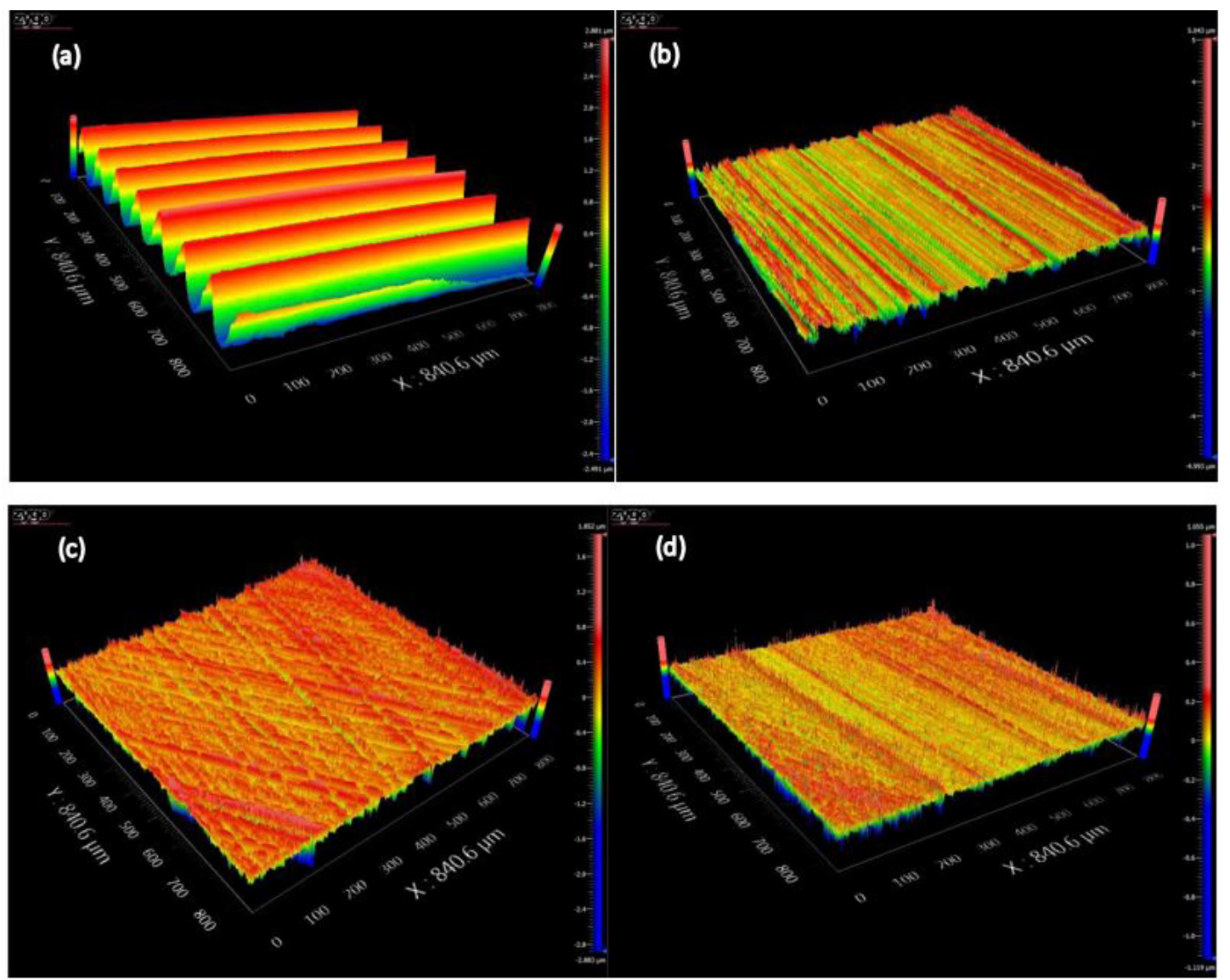

Figure 1. Typical measurements for superficial roughness of discs on the three test repetitions; (a) turning; (b) grinding; (c) honing and (d) polishing.

Table 1. Values for superficial roughness for each steel counterbody finishing: roughness average (Ra), root mean square (RMS), and total roughness (Rz).

\begin{tabular}{cccc}
\hline Finishing Process & Ra $(\boldsymbol{\mu m})$ & RMS $(\boldsymbol{\mu m})$ & $\mathbf{R z}(\boldsymbol{\mu m})$ \\
\hline Turning & $1.264 \pm 0.010$ & $1.477 \pm 0.013$ & $6.340 \pm 0.149$ \\
Grinding & $0.825 \pm 0.082$ & $1.022 \pm 0.126$ & $4.622 \pm 1.758$ \\
Honing & $0.277 \pm 0.064$ & $0.357 \pm 0.082$ & $2.236 \pm 0.499$ \\
Polishing & $0.048 \pm 0.003$ & $0.063 \pm 0.004$ & $0.575 \pm 0.096$ \\
\hline
\end{tabular}

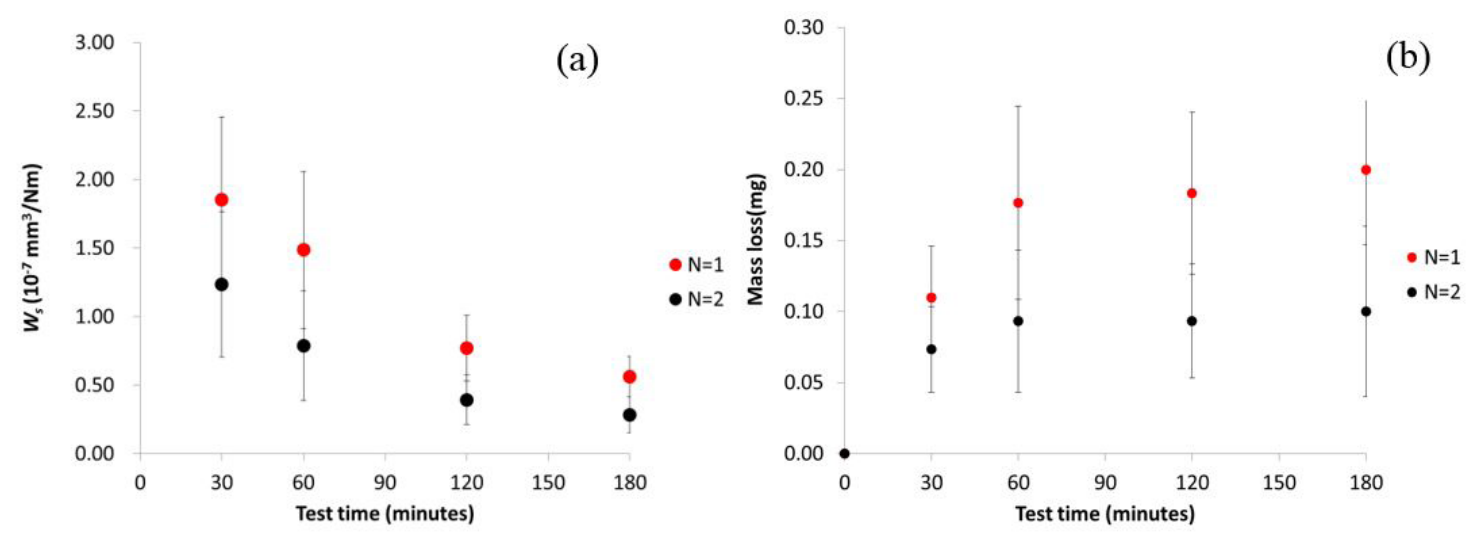

Figure 2. Specific wear rate (a) and mass loss (b) variation as a function of time for contact pressure of $2 \mathrm{MPa}$, speed of $2 \mathrm{~m} / \mathrm{s}$, turning, lubricated with ATF Dexron VI oil and temperature of $85^{\circ} \mathrm{C} . \mathrm{N}=1$ and $\mathrm{N}=2$ correspond to the two repetitions conducted. 


\subsection{Influence of roughness on the friction coefficient}

Figure 5 illustrates the relationship between the friction coefficient and roughness of the metallic disc. For the same lubrication regime, surface finishing did not influence the

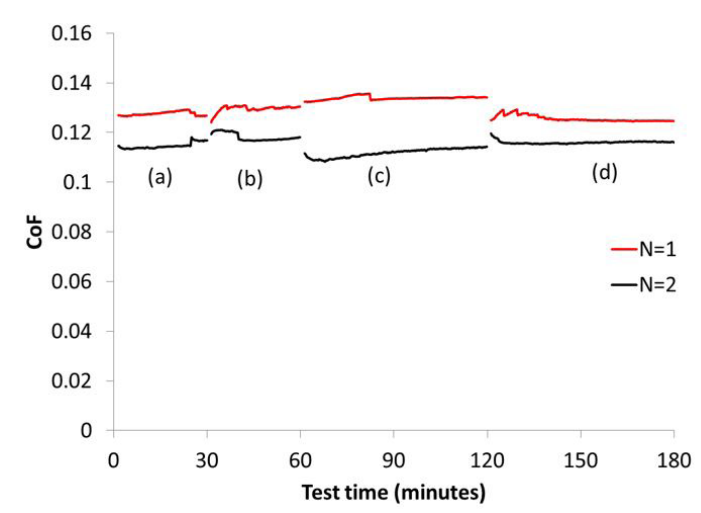

Figure 3. Friction coefficient $(\mathrm{CoF})$ variation for test periods of 0-30 minutes (a), 30-60 minutes (b), 60-120 minutes (c) and 120-180 minutes (d). $\mathrm{N}=1$ and $\mathrm{N}=2$ identify the two samples tested.

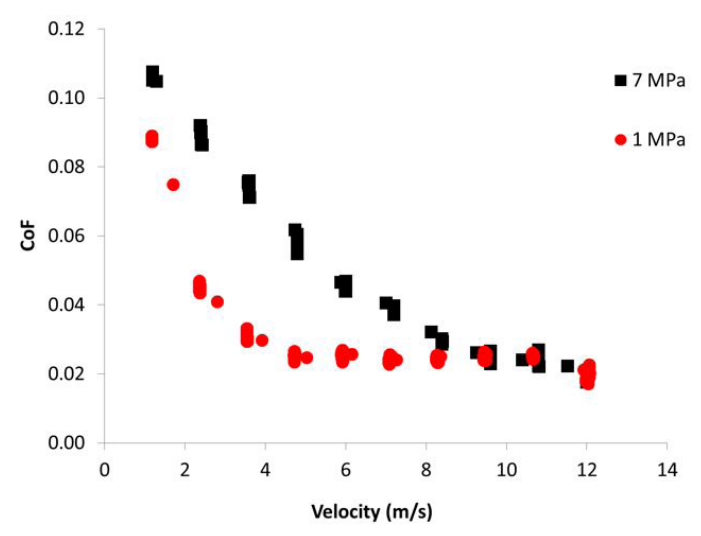

Figure 4. Change in the friction coefficient as a function of sliding speed for two different apparent contact pressures for a sample with honing finishing: $(\bullet) 1 \mathrm{MPa},(\boldsymbol{\bullet}) 7 \mathrm{MPa}$.

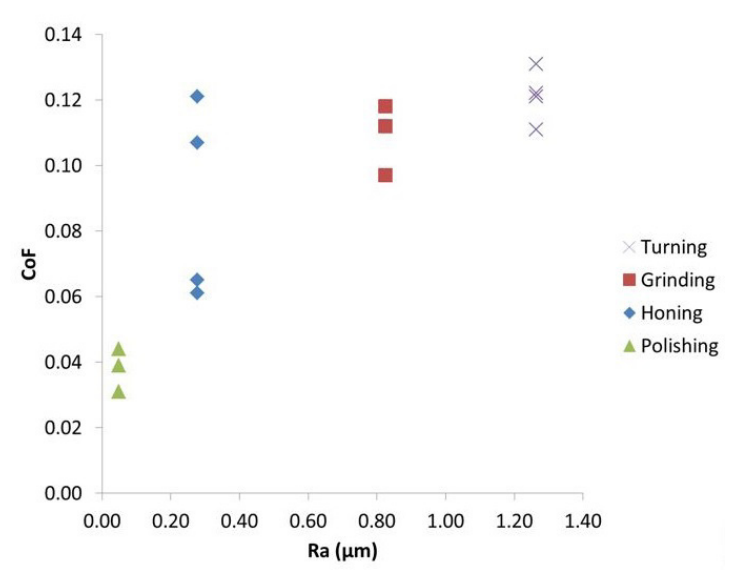

Figure 5. Influence of the metallic counterbody roughness on the friction coefficient. friction coefficient. For turning and grinding finishings, the friction coefficient observed was an average of $0.121 \pm 0.007$ and $0.109 \pm 0.009$, respectively; for polishing, it was approximately $0.038 \pm 0.005$, however for honing it displayed a greater dispersion of the results around $0.088 \pm 0.026$.

Several authors ${ }^{[6,7,11,16,17]}$ have investigated PEEK, as well as its composites, for dry sliding, with friction coefficient variations between 0.3 and 0.5 . In the present experiment, the samples submitted to turning and grinding remained within a friction coefficient rate between 0.13 and 0.10 , which was defined as boundary regime on Figure 4. A determining factor for the friction coefficient in a lubricated environment, to remain lower than the dry friction coefficient, under boundary regime, is that the lubricant ATF Dexron VI contains lubrication additives, whose efficiency was initially studied by Bowden and Tabor ${ }^{[18]}$. They observed that, by adding stearic acid to a stainless steel friction surface submitted to dry sliding, the friction coefficient was reduced to approximately 0.10 under experiment conditions. Since then, several different additives, both organic and inorganic have been studied ${ }^{[15]}$. Such additives form a film of molecular dimensions which can be absorbed either chemically or physically by the metallic surface, thus avoiding direct contact between the parts. The results of friction for honing, on the other hand, displayed greater dispersion of the data. By analyzing such results together, in Figure 4 and Figure 5, it was possible to state that for a pressure of $2 \mathrm{MPa}$ and speed of $2 \mathrm{~m} / \mathrm{s}$, the lubrication regime for this type of finishing is on the threshold between boundary and mixed regimes.

Polished samples displayed a typical friction coefficient of the hydrodynamic regime. In such regime, lubricating films are usually thick enough so as to not allow the contact between surfaces. This condition is often called optimal lubrication, as it warrants a low friction coefficient, and high wear resistance.

Experimental results for friction as a function of time, for all four types of finishing, are shown in Figure 6. The friction coefficient tended to increase as test duration increased for turning, whereas for grinding and honing the friction coefficient decreased during the test. In the case of counterbodies submitted to grinding, the friction coefficient remained stable throughout the test.

For samples submitted to turning, it is reasonable to state that the friction coefficient increases as a function of time, as explained by Greenwood and Williamson ${ }^{[19]}$. When the two surfaces come in contact during the sliding test, due to the deformation and/or cut of the polymeric material of the pins, the contact points will increase, thus increasing contact surface in comparison to the rougher surface. This results in greater shear force that will deform the material of the pin, whose hardness is lower, thus increasing the friction coefficient. Abrasion marks are detectable only on the surfaces of samples tested against discs submitted to turning, as shown on Figure 7.

One hypothesis for the friction coefficient reduction, as seen for honing and grinding, is that in a lubricated environment, a continuous film of lubricant may not be fully formed on the friction surface during the "running-in" stage, so the friction coefficient was higher during that stage. After running-in, a more continuous layer of lubricant 

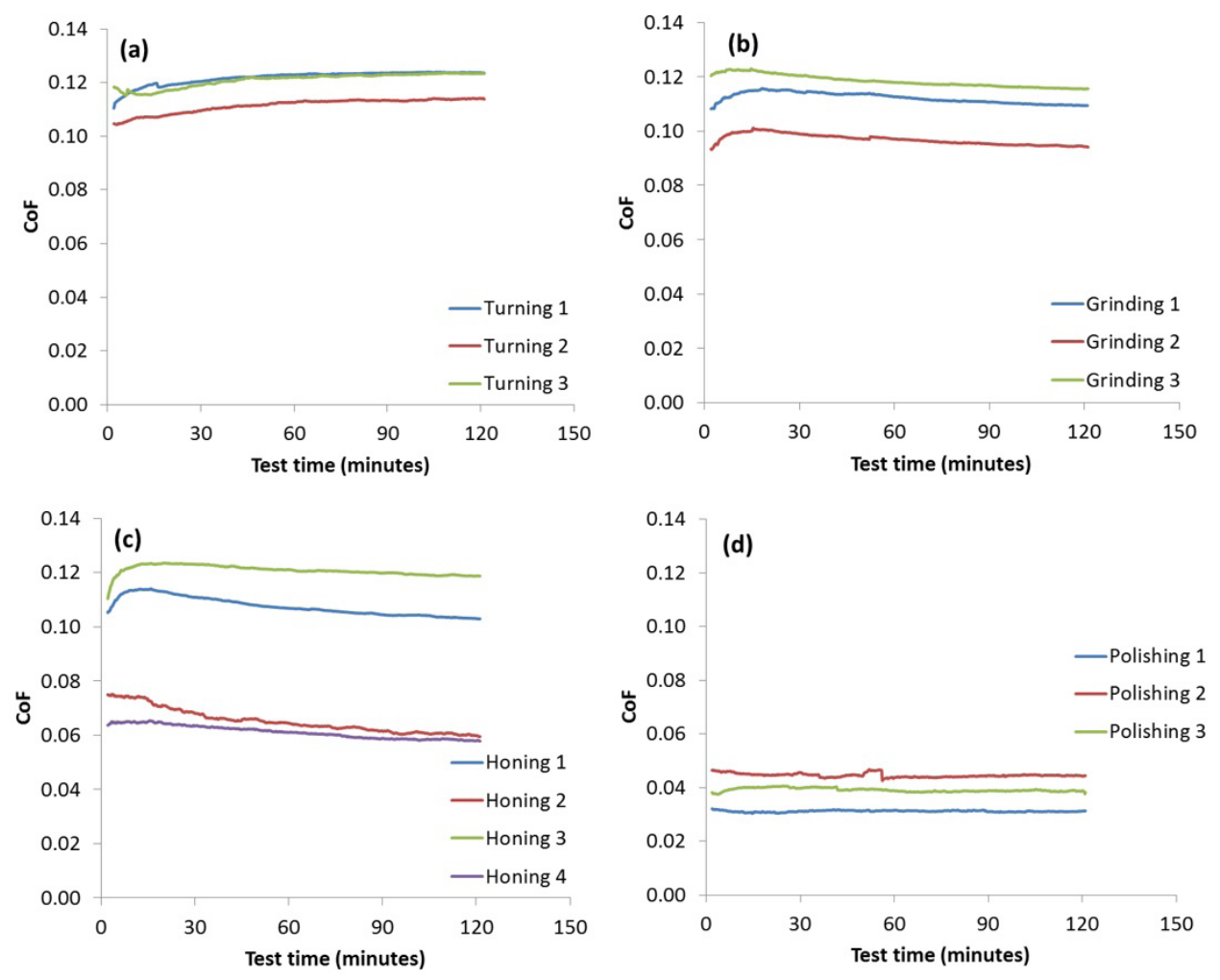

Figure 6. Results of all friction tests conducted for the four different finishings examined, as follows: (a) turning; (b) grinding; (c) honing and (d) polishing.

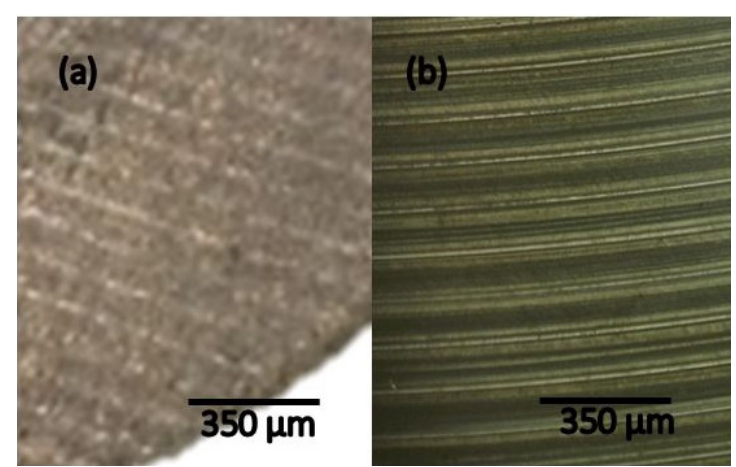

Figure 7. Contact surface of the (a) polymeric sample and (b) metallic counterbody observed through stereomicroscope.

gradually formed on the friction surface, and the direct contact between the asperities gradually diminished by the lubricating film ${ }^{[20]}$. For the polished surfaces, the friction coefficient remained stable throughout the test, as they were submitted to hydrodynamic regime, in which the friction characteristics are derived purely from the shearing of the lubricating (film).

\subsection{Influence of roughness on the wear rate}

Figure 8 shows the effect of the four finishing options for the counterbody in relation to wear rate for the material studied. Specific wear rate varied approximately 4 -fold, when

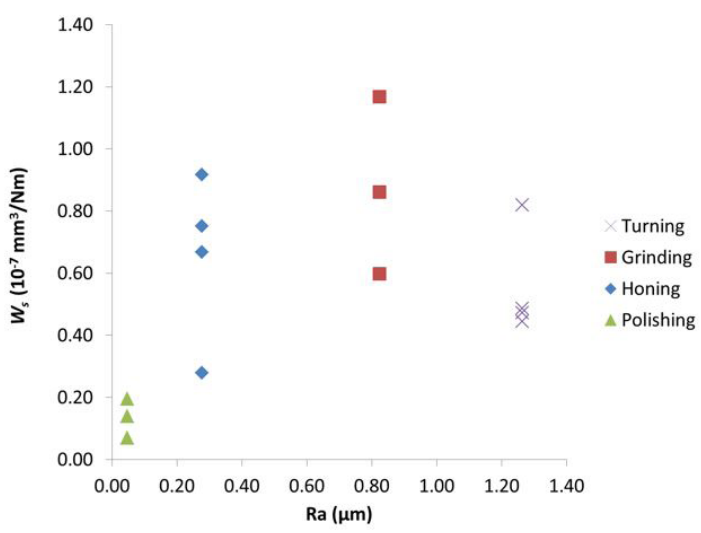

Figure 8. Influence of the metallic counterbody roughness on the wear rate of the PEEK pin.

finishings with lower Ra and higher Ra were compared. A different behavior was observed in dry wear conditions of the same material, as described by Friedrich et al. ${ }^{[10]}$. In that case, the average wear rate remained constant regardless of the roughness, which, to some extent, was also observed in lubricated environment, however, for each lubricating regime. The specific wear rate for dry conditions ( $p v \approx 5 \mathrm{MPa} . \mathrm{m} / \mathrm{s}$ ) was 8 to 20 times greater than the wear in a lubricated environment ( $p v \approx 4 \mathrm{MPa} \cdot \mathrm{m} / \mathrm{s}$ ) under boundary regime. The mean wear rate generated by the counterbodies submitted 


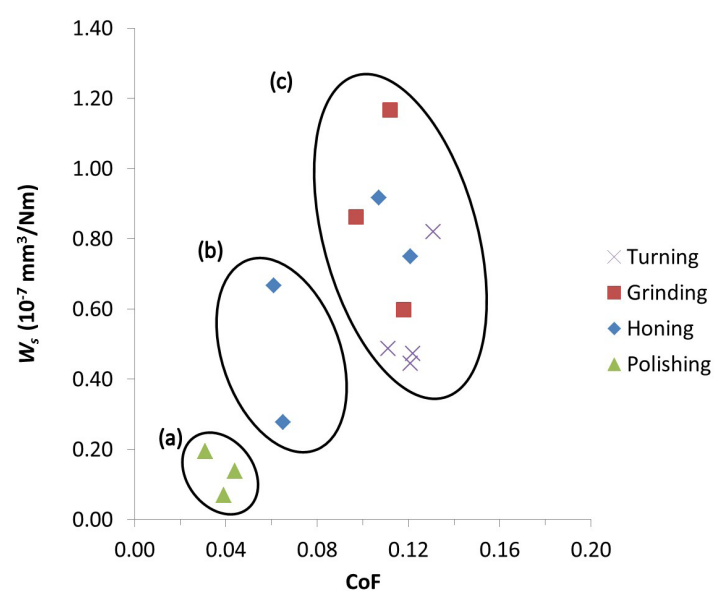

Figure 9. Polymer wear rate versus friction coefficient for the different counterbody surface finishing. (a) hydrodynamic; (b) mixed and (c) boundary lubrication regimes.

to turning, grinding, and honing were very similar, while the polished samples displayed a markedly lower wear. This happens because under hydrodynamic lubrication regime, the lubricant film is thick enough to prevent the contact between the solid parts, thus significantly reducing wear rate between components.

Figure 9 shows the wear rate as a function of the friction coefficient observed for different counterbody finishings. In this graph, the relationship between the friction coefficient and the specific wear rate for each finishing is clear. Although the wear increased with the increase of the friction coefficient, there does not seem to be a direct correlation with the roughness of the counterbody, but with the lubrication regime in which the system is operating.

In these tests, neither debris nor thin film were observed by optical stereomicroscope in any of the counterbodies, not even on the samples submitted to turning or grinding, which operated under boundary regime. However, both debris and films adhered to the surface of the counterbody were observed in tests conducted under dry conditions, depending on the roughness ${ }^{[2]}$. Lubricant flow, besides significantly reducing the heat caused by friction and contact temperature, also removed the debris form the contact region, thus reducing wear caused by abrasion.

\section{Conclusions}

The present work studied the tribological properties of PEEK combined 30\% carbon fiber in an oil-lubricated environment for four different counterbody finishings. As a result we reached the following conclusions:

i. The steady-state wear regime happened 120 minutes after the stabilization of the wear rate and the friction coefficient.

ii. For the pressure range between 1 and $7 \mathrm{MPa}$, the friction coefficient for the boundary regime was 0.09 to 0.13 , the mixed regime was between 0.04 and 0.09 , and for the hydrodynamic regime it was below 0.04 . iii. Tribological characteristics of PEEK were shown to be much more sensitive to the lubrication regime than to superficial roughness; however the lubrication regime was also defined by roughness.

iv. The average wear rates generated with counterbodies summited to turning, grinding, honing were very similar, whereas polished samples displayed a much lower wear, due to the fact that they were under hydrodynamic regime.

\section{Acknowledgements}

The authors wish to thank Mr. Ricardo Elhke and Mr. Kida Kazuhiro from Victrex for kindly supplying the polymeric material, as well as the test benches, and for the invaluable technical discussions.

\section{References}

1. America Chemistry Council. (2014). Plastics and polymer composites technology roadmap for automotive markets. Washington: America Chemistry Council.

2. Nunez, E. E., \& Polycarpou, A. A. (2015). The effect of surface roughness on transfer of polymer films under unlubricated testing conditions. Wear, 326-327(15), 74-83. http://dx.doi. org/10.1016/j.wear.2014.12.049.

3. Gutiérrez, J. C., Rubio, J. C. C., \& Faria, E. (2014). Usinabilidade de materiais compósitos poliméricos para aplicações automotivas. Polímeros. Ciência e Tecnologia, 24(6), 711-719. http://dx.doi. org/10.1590/0104-1428.1582.

4. Greco, A. C., Erck, R., Ajayi, O., \& Fenske, G. (2011). Effect of reinforcement morphology on high-speed sliding friction and wear of PEEK polymers. Wear, 271(9-10), 2222-2229. http://dx.doi.org/10.1016/j.wear.2011.01.065.

5. Altstaedt, V., Werner, P., \& Sandler, J. (2003). Rheological, mechanical and tribological properties of carbon-nanofibre reinforced poly (ether ether ketone) composites. Polimeros: Ciência e Tecnologia, 13(4), 218-222. http://dx.doi.org/10.1590/ S0104-14282003000400005.

6. Zhang, G., \& Schlarb, A. K. (2009). Correlation of the tribological behaviors with the mechanical properties of poly-ether-etherketone (PEEKs) with different molecular weights and their fiber filled composites. Wear, 266(1-2), 337-344. http://dx.doi. org/10.1016/j.wear.2008.07.004.

7. Elliott, D. M., Fisher, J., \& Clark, D. T. (1998). Effect of counterface surface roughness and its evolution on the wear and friction of PEEK and PEEK-bonded carbon fibre composites on stainless steel. Wear, 217(2), 288-296. http:// dx.doi.org/10.1016/S0043-1648(98)00148-3.

8. Birkett, A., \& Lancaster, J. K.(1985). Counterface effects on the wear of a composite dry-bearing liner. In JSLE International Tribology Conference (pp. 8-10). Tokyo: Elsevier.

9. Stachowiak, G. W., \& Batchelor, A. W.(2005). Engineering tribology. Oxford: Butterworth Heinemann.

10. Friedrich, K., Karger-Kocsis, J., \& Lu, Z. (1991). Effects of steel counterface roughness and temperature on the friction and wear of PEEK composites under dry sliding conditions. Wear, 148(2), 235-247. http://dx.doi.org/10.1016/00431648(91)90287-5.

11. Ramachandra, S., \& Ovaert, T. C. (1997). The effect of controlled surface topographical features on the unlubricated transfer and wear PEEK. Wear, 206(1-2), 94-99. http://dx.doi. org/10.1016/S0043-1648(96)07354-1. 
12. Eiss, N. S., Wood, K. C., Herold, J. A., \& Smyth, K. A. (1979). Model for the transfer of polymer to rough, hard surfaces. Journal of Lubrication Technology, 101(2), 212-218. http:// dx.doi.org/10.1115/1.3453326.

13. Victrex Materials Properties Guide. (2014, 20 november). Retrieved in 24 July 2015, from http://www.victrex.com

14. ASTM International. ASTM G-99-04: standard test method for wear testing with pin-on-disk apparatus metals test methods and analytical procedure (Vol. 03.02, Section 3). West Conshohocken: ASTM.

15. Hamrock, B. J., Schmid, S. R., \& Jacobson, B. O.(2004). Fundamentals of fluid film lubrication (2nd ed.). New York: Marcel Dekker.

16. Lu, Z. P., \& Friedrich, K. (1995). On sliding friction and wear of PEEK and its composites. Wear, 181-183(2), 624-631. http:// dx.doi.org/10.1016/0043-1648(95)90178-7.

17. Zhang, G., Rasheva, Z., \& Schlarb, A. K. (2010). Friction and wear variations of short carbon fiber (SCF)/PTFE/graphite
(10 vol.\%) filled PEEK: effect of fiber orientation and nominal contact pressure. Wear, 268(7-8), 893-899. http://dx.doi. org/10.1016/j.wear.2009.12.001.

18. Bowden, F. P., \& Tabor, D. (1950). Friction and lubrication of solids. Oxford: Clearendon Press.

19. Greenwood, J. A., \& Williamson, J. B. P. (1966). Contact of nominally flat surfaces. Proceedings of the Royal Society of London. Series A, Mathematical and Physical Sciences, 295(1442), 300-319. http://dx.doi.org/10.1098/rspa.1966.0242.

20. Zhang, Z. Z., Xue, Q. J., \& Shen, W. C. (1997). Tribological properties of metal-plastic multilayer composites under oil lubricated conditions. Wear, 210(1-2), 195-203. http://dx.doi. org/10.1016/S0043-1648(97)00040-9.

Received: July 24, 2015

Revised: Mar. 23, 2016

Accepted: Mar: 31, 2016 